\title{
Current and future prospects of integrating traditional and alternative medicine in the management of diseases in Tanzania
}

\author{
M. J. MOSHI \\ Institute of Traditional Medicine, Muhimbili University College of Health Sciences, \\ P.O. Box 65001, Dar es Salaam, Tanzania \\ Email:mmoshi@muchs.ac.tz
}

\begin{abstract}
Traditional medicine and medicinal plants, in general, continue to be a powerful source of new drugs, now contributing about $90 \%$ of the newly discovered pharmaceuticals. Traditional medicine continues to provide health coverage for over $80 \%$ of the world population, especially in the developing world. The past and the present are all full of living examples of discoveries of drugs, ranging from anticancer, antiasthma, antidiabetic, antihypertensives and many others which owe their origin to traditional medicine. The current era of HIV/AIDS is not short of contributions from traditional medicine. The recent discovery of the non-nucleoside reverse transcriptase inhibitor (NNRTI), calanolide A, is a new addition from traditional medicine. Many more such discoveries are yet to come. While this potential is much acknowledged, little has been done in African countries, to utilize the plants that are already known and proven to be safe for use by patients. A number of plants could be widely cultivated for local industrial production of medicines and herbal nutritional supplements. There is need to ensure that what is known is made use of, for financial gain, and for improvement of the health of our people. We need to establish the necessary expertise for development of traditional medicines and deliberate efforts should be made to encourage local industrial production of traditional/herbal medicines so that cultivation may become possible and hence contribute to poverty reduction.
\end{abstract}

Keywords: Traditional medicine, alternative medicine, diseases, Tanzania

\section{Introduction}

The world is currently facing a number of health challenges, partly due to expanded boundaries of diseases as a result of global warming, improved means of transportation and increased migration of people. It is also acknowledged that the change of lifestyle in the developing world, where people are now leading sedentary lives, and have greatly changed types of food essentially consuming more refined foods has now led to increase in the prevalence of glucose intolerance (King \& Rewers, 1993). Likewise there have emerged new diseases such as HIV/AIDS, Ebola, and human spongiform encephalopathy (Budka et al., 1995; Van Everbroeck et al., 2000; Brown et al., 2004) that do not yet have a cure. Re-emergence of diseases like tuberculosis and the emergence of pathogens that are resistant to the currently available chemotherapeutic agents, is yet another challenge of our times. The living example is the emergence of multi-drug resistant (MDR) Mycobacterium tuberculosis. Malignant tumors and some important parasites, like Plasmodium falciparum and Candida albicans are also developing resistance, thus making management of diseases more and more difficult.
Amidst this crisis, the synthetic chemist is long recognized to have failed to address these health challenges. The only rational alternative is therefore, traditional medicine, which according to WHO supports more than $80 \%$ of the population in developing countries, and it is now widely accepted that traditional medicines are more affordable, less toxic, and have a wide acceptance around the world (Cowan, 1999; WHO, 2002).

Nature has been a source of medicinal treatments for thousands of years, and plant-based systems continue to play an essential role in the primary health care. It is estimated that 25 to $50 \%$ of all current pharmaceuticals are derived from plants (Cowan, 1999). In fact, it is now believed that plant based systems contribute $90 \%$ of the newly discovered pharmaceuticals. Nature has provided many of the effective anticancer agents in current use, such as the microbially derived drugs, dactinomycin, bleomycin, and doxorubicin, and the plant-derived drugs vinblastine, irinotecan, topotecan, etoposide, and paclitaxel (Cragg et al., 1997). Traditional medicine, has particularly, been a good source of these plant derived drugs. This paper examines some evidences and indicators of 
prospects for the use of traditional medicines in the management of different diseases, and some efforts in the discovery of drugs for the management of HIV/AIDS and associated opportunistic conditions. Literature reports and some results generated from our own research have been used to build up a case for the possibility that traditional medicine could be a source of drugs for the management of patients in Tanzania.
Terminalia sericea (Moshi \& Mbwambo, 2005) and Terminalia mollis (M. Moshi \& Z. Mbwambo, unpublished), which are used in traditional medicine in Tanzania have potential to yield anticancer compounds. Work done using brine shrimps as a screening tool shows that extracts of the two plants have activity which compares very favorably with the standard drug cyclophosphamide (Table 1). Ongoing studies on the combretastatins, and other

Table 1: The brine shrimp lethality test of Terminalia sericea root extracts. The results are reported as $\mathrm{LC}_{50}$ values with the $\mathbf{9 5 \%}$ confidence intervals (CI).

\begin{tabular}{lll}
\hline Extract type & LC $_{\mathbf{5 0}}$ & $\mathbf{9 5 \%} \mathbf{C I}$ \\
\hline Petether extract & 121.0 & $108.0-135.5$ \\
Dichloromethane extract & 29.9 & $21.2-42.2$ \\
Ethylacetate & 16.4 & $11.8-22.6$ \\
Dichloroethane:methanol $(1: 1)$ & 5.4 & $4.1-7.2$ \\
Methanol extract & 16.9 & $15.2-18.8$ \\
$80 \%$ Ethanol extract & 17.4 & $11.4-26.5$ \\
Aqueous extract & 5.4 & $3.5-8.4$ \\
Butanol extract & 5.8 & $4.1-8.1$ \\
Cyclophosphamide & 16.3 & $10.6-25.2$ \\
\hline
\end{tabular}

\section{Traditional medicine in the discovery of anticancer drugs}

One good example is the plant Catharanthus rosea which was used in Madagascar for treatment of diabetes. Through use, it was later observed that extracts of the plant suppress the bone marrow. Follow up of this observation led to the discovery and the isolation of the anticancer compounds vincristine, vinblastine, and vinorelbine. The compound taxol which was first isolated from the Pacific yew, Taxus brevifolia, was found to have anticancer activity. This has now resulted in the synthesis of the analogues paclitaxcel and docetaxel, which now constitute a new class of broad spectrum anticancer compounds.

Plants of the family Combretaceae are widely used in traditional medicine in South Africa (Eloff, 1999) and Tanzania (Fyhrquist et al., 2004; Moshi $\&$ Mbwambo, 2005). The plants of this family are now a source of combretastatins, a new class of antimitotic drugs that also inhibit angiogenesis and are currently being developed for the treatment of cancer. Work done in our laboratory has shown that compounds, from this family hold a promise for new anticancer drugs.

\section{Traditional medicine in the discovery of antimalarial drugs}

Cinchona bark was used for the treatment of malaria by South American Indians. This led to the isolation of quinine in the seventeenth century. Based on the structure of quinine other analogues have been synthesized. Mefloquine is a quinoline methanol with a structure similar to that of quinine. Other antimalarials which were synthesized based on the structure of quinine include the 4-aminoquinolines (chloroquine and amodiaquine), 8-aminoquinolines (primaquine and tefenaquine), and the aryl alcohols (halofantrine, lumefantrine, and pyronaridine). Recently, from the Chinese traditional medicine, quinghasou, the antimalarials artemisinin, dihydroartemisinin, artemether, and arteether have been discovered (Meshnick et al., 1996). A number of other plants from traditional medicine have shown antimalarial activity and have potential for discovery of future antimalarials. 


\section{Traditional medicine in the discovery of anti-asthma drugs}

Khellin from Amni visnaga was used in the USA as a bronchodilator. It was then discovered that after prolonged use it produces nausea and vomiting. As an attempt to synthesize khellin analogues with fewer side effects the antiasthma drug chromolyn (Sodium chrogycate was discovered (Sneader, 1985). Sodium chromogylycate is now used to stabilize the membranes of macrophages and prevent degranulation, and hence release of mediators of broncho-constriction in asthmatic patients.

\section{Traditional medicine in the discovery of antidiabetic drugs}

Galega officinalis (L.) was used ethnomedically for the treatment of diabetes. Phytochemical work led to the isolation of the antihyperglycaemic compound galegine from the plant. Further structure activity studies and modification of galegine led to the synthesis of metformin and eventually the other biguanide oral hypoglycaemic agents (Sneader, 1985). Harunganin was recently isolated from a Tanzanian plant, Harungana madagascariensis and is now patented in the USA for treatment of diabetes (Inman \& Luo, 1998).

Other compounds recently isolated from traditionally used plants and patented for treatment of diabetes include cryptolepine (Bierer et al., 1998a,b; Luo et al., 1998), maprouneacin (Carney et al., 1999), 3ß,30-dihydroxylupen-20(29)-en-2-one (Inman \& Reed, 1997,1998), vismin (Inman \& Luo, 1998), and quinones SP18904 and SP18905 (Luo et al., 1999). The most interesting discovery was nordihydroguaiaretic acid (ndga) (Luo et al., 1998) which, besides being active orally in diabetic mice, also lowered cholesterol levels.

\section{Traditional medicine in the discovery of anti-HIV drugs}

The use of traditional medicines for the management of HIV/AIDS patients is directed to three main areas; direct effect on the virus, immunostimulant activity, and treatment of opportunistic infections. A number of plants have now been identified from random screening or from traditional systems of treatment that interfere with nearly all stages of the viral life cycle. Compounds have been reported that inhibit virus-cell fusion, reverse transcription, virus adsorption, and proteolytic cleavage (Vlietinck et al., 1998; Wang et al., 1998; Uchiumi et al., 2003). A good number of plants containing these compounds, such as Phyllanthus amarus (Notka et al., 2004), Phyllanthus niruri (Naik \& Juvekar, 2003), Salvia miltiorrhiza (Abd-Elazem et al., 2002), Shepherdia argentea (Yoshida et al., 1996), Viola yedoensis, Arctium lappa, Epimedium grandiflorum, Glycyrrhiza uralensis and Castanospermum australe (WHO, 1989), and Croton tiglium (Nakamura, 2004) originate from traditional medicine. Other traditionally used medicines that have shown anti-HIV activity are Aspilia pluriseta and Rumex bequaertii (Cos et al., 2002). In a recent study done on 21 plant species belonging to 14 families of plants, that are used in Ethiopian traditional medicine, extracts of four plants, Bersama abyssinica Fresen, Combretum paniculatum Vent., Dodonaea angustifolia L.f., and Ximenia americana L. displayed anti-HIV activity against both HIV-1 and HIV-2 strains (Asres et al., 2001). Similarly screening of plants used in traditional medicines of other countries has led to identification of interesting anti-HIV activity (Abdel-Malek et al., 1996; Piras et al., 1997; Li et al., 1993).

The most recent success story is the discovery of (+)-Calanolide A, a novel non-nucleoside HIV-1reverse transcriptase inhibitor (NNRTI), which was first isolated from a Malaysian plant, Calophyllum lanigerum (Currens et al., 1996; Buckheit et al., 1999; Creagh et al., 2001). The anti-HIV properties of Calanolide A show that it is effective towards multiple NNRTI-resistant mutations that include the highly resistant Y181C mutation. Clinical viral isolates that are resistant to nucleoside analogues have been shown to be hypersensitive to the antiviral effects of Calanolide A. In laboratory experiments Calanolide A also works synergistically towards HIV when used with other anti-HIV drugs. The drug is being developed by Sarawak MediChem and is now undergoing phase III clinical trials. A recently published article reported results showing that Calanolide A is also active against both drug-sensitive and drug-resistant Mycobacterium tuberculosis (Xu et al., 2004). 
Sutherlandia frutescens and Lobostemon trigonu are two plants that are marketed in South Africa for the treatment of HIV/AIDS patients. A recent study has, now provided proof, that the two plants have inhibitory activity against HIV-1 reverse transcriptase activity (Harnett et al., 2005). Clinicians treating HIV+ patients with Sutherlandia tablets produced by the South African company Phyto Nova have reported increase in CD4 and reduction of viral load. Sutherlandia is also reported to have apoptotic activity against human cancer cell lines (Chinkwo, 2005), thus suggesting an additional potential for dealing with opportunistic malignancies in HIV patients.

Aloe vera has also being very popular in South Africa. The plant contains a large variety of amino acids, enzymes, vitamins and minerals and it comes closer than any other known plant to the duplication of life's essential substances in the biochemistry of the human body. It has natural healing and detoxifying powers and works gently within the intestinal tract to help break down impacted food residues and thoroughly cleanse the bowel. It can help ease constipation and prevent continuing diarrhoea, setting a regularity to the bowel. All this helps to reduce discomfort and bloating. Naturally, as these symptoms are eased, so the stress associated with the discomfort is also reduced. Aloe vera is a stimulant to the immune system, a powerful antiinflammatory, and analgesic and is able to speed up cell growth. Aloe vera contains a large number of mucopolysaccharides (basic sugars) which are found in every cell in the body and contains large numbers of nutrients including vitamins E, C, B1, 2, 3 , and 6 as well as iron, manganese, calcium and zinc. Seven essential amino acids and fatty acids are also found in Aloe vera (Davis \& Leitner, 1989; Davis \& Rosenthal, 1989; Pulse \& Uhlig, 1990; Sato, 1990; McCluggage \& Higdon, 1999). This plant should be promoted as a nutritional supplement to HIV/AIDS patients, who are likely to realize a lot of benefit from its use. The big question is whether such use may not have interactions, particularly with concurrent use with anti-retroviral drugs. However, this should be one of the areas that need intensive scientific studies.

\section{Traditional medicines in the treatment of bacterial infections}

The other area where traditional medicines can offer hope is in the treatment of opportunistic infections. Our experience shows that there are a number of plants with a good potential for offering solutions to resolution of bacterial, fungal, viral, protozoa, and other opportunistic infections. There are now abundant reports of useful activities of plants of the genera Combretum and Terminalia. A number of species of Combretum and Terminalia from South Africa have antibacterial activity (Eloff, 1999). The plants in the two genera are heavily used in traditional medicine in South Africa with an annual consumption of 20.2 tons per year in Kwazulu Natal (Eloff, 1998). In Tanzania the plants in the two genera are also popularly used in traditional medicine for the treatment of bacterial infections (Fyhquist et al., 2004, 2005; Moshi \& Mbwambo, 2005). Combretum micranthum which is used traditionally in West Africa for treatment of biliary fever, colic and vomiting, showed good antibacterial activity against both gram positive and gram negative bacteria.

In a recent study we looked at the antibacterial properties of Terminalia sericea (Moshi \& Mbwambo, 2005) and Terminalia mollis (unpublished results), in which we showed that these two plants growing in Tanzania have antimicrobial activity, thus confirming reports from traditional healers in Iringa, Tabora and Bukoba where they were collected. The two plants are used for treatment of bacterial infections such as gonorrhoea and tuberculosis, and also dysentery, diarrhoea and malaria.

\section{Traditional medicines for treatment of fungal infections}

A number of plants used in traditional medicines are currently being identified for the treatment of opportunistic fungal infections in HIV patients (Fyhrquist et al., 2004; Motsei et al., 2003). Some of the already identified plants could be used as oral mouth preparations (Motsei et al., 2003), and others could be made in the form of ointments or creams for use on the skin. Studies done on some 
Combretaceae plants indicate the possibility of getting clinically useful antifungal activity, particularly against Candida albicans and other yeast-like fungi (Moshi \& Mbwambo, 2005). In a recent ethnomedical survey, in Morogoro rural (Mikese), Singida, Lushoto, and Coast region (Chalinze, Bagamoyo, Chamakwesa, and Mabwepande) in Tanzania, 58 plants used for treatment of fungal infections were identified. Out of these plants 10 gave very good antifungal activity in the laboratory. Other plants collected in Bukoba,
Tanzania have also indicated possibility that they may be good for treatment of fungal infections. These plants and others are currently being screened for toxicity using the brine shrimps test in our laboratory. The preliminary results show that a good number of the plants for treatment of fungal infections have a good safety margin (Table 2). Some of these plants are being tested for the treatment of topical fungal infections, and already there are good responses among patients using them.

Table 2: Brine shrimp lethality of aqueous ethanolic extracts of plants used traditionally for treatment of fungal infections

\begin{tabular}{llll}
\hline Binomial name & Vernacular name & Part tested & LC $\left._{\mathbf{5 0}} \mathbf{\mu g} / \mathbf{m l} \mathbf{( 9 5 \%} \mathbf{C I}\right)^{*}$ \\
\hline Acacia nilotica & Mkame & Leaves & $108.5(87.8-134.0)$ \\
Acalypha fruticosa & Siaiti & Roots & $23.9(16.5-34.7)$ \\
Acalypha fruticosa & Siaiti & Leaves & $113.9(91.2-142.3)$ \\
Aloe lateritia & Mapuni, Nyamviri & Leaves & $19.1(13.2-27.8)$ \\
Cordia Africana & Mngwengweni & Roots & $211.4(117.6-380.1)$ \\
Cyphosterma hilderbrandtii & Damanya mwili & & $25.7(16.9-39.0)$ \\
Elaeodendron schlechteranum & Mkandekande & Stem bark & $37.5(28.1-50.1)$ \\
Euphorbia heterophylla & Loo & Leaves & $80.2(57.3-112.3)$ \\
Ficus sur & Mkuyu & Bark & $146.1(116.1-183.9)$ \\
Hypericum roeperanum & Mwambaziwa & Leaves & $46.6(34.2-63.6)$ \\
Jatropha multifida & Maugamwipoli & Leaves & $21.7(16.4-28.7)$ \\
Jatropha multifida & Maugamwipoli & Stem & $58.3(41.3-82.4)$ \\
Jatropha multifida & Maugamwipoli & Roots & $26.1(17.3-39.2)$ \\
Khaya anthotheca & Mgolaminzi & Stem bark & $38.7(28.6-52.2)$ \\
Kigelia africana & Mungungu & Roots & $7.2(3.9-13.8)$ \\
Kigelia africana & Mungungu & Fruits & $4.6(3.2-6.6)$ \\
Lannea stuhlmannii & Muhungilo & Leaves & $25.3(16.6-38.8)$ \\
Ocimum suave & Suameno & Leaves & $16.7(11.6-24.1)$ \\
Rapanea melanophloeus & Mpaja & Stem bark & $152.4(84.6-274.5)$ \\
Rapanea melanophloeus & Mpaja & Leaves & $12.1(8.6-17.2)$ \\
Spirostachys africana & Muhoza & Leaves & $16.4(9.4-28.8)$ \\
Tegetes minuta & Mbangi & & $19.9(14.5-27.3)$ \\
Zehneria seabra & Fuia & Leaves & $138.1(93.7-203.4)$ \\
Ziziphus pubercens & Inyigrishi & Leaves & $68.2(50.5-92.1)$ \\
Cyclophosphamide & Standard drug & & $16.3(10.6-25.2)$ \\
\hline & The & &
\end{tabular}

*The results are reported as $\mathrm{LC}_{50}$ values with the $95 \%$ confidence intervals 


\section{Efforts to use already established plants}

Prospects for incorporating traditional medicines into the health care system are quite high, if appropriate measures are taken to ascertain the claimed activities, and obvious toxicities that may prevent immediate use. In many instances traditional healers use these plants in a manner that avoids the toxic manifestations. Biological testing coupled with a quick evaluation for toxicity should allow an accelerated use of traditional medicines without a lot of fear about toxicity, especially where such medicines are going to be used for a short period, such as in the treatment of bacterial, fungal and protozoan infections. For example, Terminalia sericea gave positive antibacterial activity against gram positive and gram negative bacteria and antifungal activity against $C$. albicans, but it also showed toxicity on brine shrimps, suggesting either outright toxicity or presence of anticancer activity, since the results compared very well with the values obtained with the standard anticancer drug cyclophosphamide (Moshi \& Mbwambo, 2005). It is known that Combretaceae plants contain combretastatins, which have anticancer activity.

Our Institute is now piloting the production of herbal formulations of already proven plants. Currently herbal preparations for benign prostatic hypertrophy, peptic ulcers, coughing, livers cirrhosis and asthma are being produced at the Institute. Efforts are underway to standardize these formulations and make them available to many more people in Tanzania. The production is going hand in hand with promotion of cultivation of some of the medicinal plants such as Adansonia digitata, Moringa oleifera, Hibiscus subdariffa variety Rosera, and Aloe vera. It is expected to involve the community in the cultivation of these medicinal plants.

\section{Conclusion}

Traditional medicines are now the mainstay of drug discovery, for treatment of old and emerging diseases. The options of using them as herbal medicines or for isolation of patentable compounds remain attractive to researchers in Tanzania and elsewhere. However, there is need to ensure that what is known is made use of, for financial gain, and for improvement of the health of our people. We need to establish the necessary expertise for development of traditional medicines and deliberate efforts should be made to encourage local industrial production of traditional/herbal medicines so that cultivation may become possible and hence contribute to poverty reduction.

\section{References}

Abdel-Malek, S., Bastien, J.W., Mahler, W.F., Jia, Q., Reinecke, M.G., Robinson, W.E. Jr, Shu, Y. \& Zalles-Asin, J. (1996) Drug leads from the Kallawaya herbalists of Bolivia.1. Background, rationale, protocol and antiHIV activity. Journal of Ethnopharmacology 50, 157-166.

Abd-Elazem, I.S., Chen, H.S., Bates, R.B. \& Huang, R.C. (2002) Isolation of two highly potent and non-toxic inhibitors of human immunodeficiency virus type 1 (HIV-1) integrase from Salvia miltiorrhiza. Antiviral Research 55, 91-106.

Asres, K., Bucar, F., Kartinig, T., Witvrouw, M., Pannecoupue, C. \& De Clercq, E. (2001) Antiviral activity against human immunodeficiency virus type $1(\mathrm{HIV}-1)$ and type 2 (HIV-2) of ethnobotanically selected Ethiopian medicinal plants. Phytotherapy Research 15, 62-69.

Bierer, D.E., Fort, D.M., Mendez, C.D., Luo, J., Imbach, P.A., Dubenko, L.G., Jolad, S.D., Gerber, R.E., Litvak, J., Lu, Q., Zhang, P., Reed, M.J., Waldeck, N., Bruening, R.C., Naomesi, B.K., Hector, R.F., Carlson, T.J. \& King, S.R.(1998a) Ethnobotanicaldirected discovery of the antihyperglycemic properties of cryptolepine: its isolation from Cryptolepis sanguinolenta, synthesis, and in vitro and in vivo activities. Journal of Medicinal Chemistry 41, 894-901.

Bierer, D.E., Dubenko, L.G. Zhang, P., Lu, Q., Imbach, P.A., Garofalo, A.W., Phuan, P., Fort, D.M., Litvak, J., Gerber, R.E., Sloan, B., Luo, J., Cooper, R. \& Reaven, G.M. (1998b) Antihyperglycemic activities of cryptolepine analogues: an ethnobotanical lead structure isolated from Cryptolepis sanguinolenta. Journal of Medicinal Chemistry 41, 2754-2764. 
Brown, P., Gibbs Jr., C.J., Rodgers-Johnson, P., Asher, D.M., Sulima, M.P., Bacote, A. \& Gajdusek, D.C. (2004) Human spongiform encephalopathy: The National Institute of Health series of 300 cases of experimentally transmitted disease. Annals of Neurology 35, 513-529.

Buckheit, R.W., Jr., White, E.L., Fliakas-Boltz, V., Russell, J., Stup, T.L., Kinjerski, T.L., Osterling, M.C., Weigand, A. \& Bader, J.P. (1999) Unique anti-human immunodeficiency virus activity of the nonnucleoside reverse transcriptase inhibitors calanolide A, costatolide and dihydrocostatolide. Antimicrobial Agents and Chemotherapy 43,1827-1834.

Budka, H., Aguzzi, A., Brown, P., Brucher, J.M, Bugiani, O., Collinge, J., Diringer, H., Gullotta, F., Haltia, M. \& Hauw, J.J. (1995) Neuropathological diagnostic criteria for Creutzfeldt-Jakob disease (CJD) and other human spongiform encephalopathies (prion diseases). Brain Pathology 5, 319-322.

Carney, J.R., Krenisky, J.M., Williamson, R.T., Luo, J., Carlson, T.J., Hsu, V.L. \& Moswa, J.L. (1999) Maprouneacin, a new daphnane diterpenoid with potent antihyperglycemic activity from Maprounea africana. Journal of Natural Products 62, 345-347.

CDC (1990) Guidelines for national human immunodeficiency virus case surveillance, including monitoring for human immunodeficiency virus infection and acquired immunodeficiency syndrome. MMWR Morbidity and Mortality Weekly Reports 48 (RR-13), 1-27, 29-31.

Chinkwo, K.A. (2005) Sutherlandia frutescens extracts can induce apoptosis in cultured carcinioma cells. Journal of Ethnopharmacology 98, 163-170.

Cos, P., Hermans, N., De, B.T., Apers, S., Sindambiwe, J.B., Witvrouw, M., De, C.E, Vanden, B.D., Pieters, L. \& Vlietinck, A.J. (2002) Antiviral activity of Rwandan medicinal plants against human immunodeficiency virus type-1 (HIV-1). Phytomedicine 9, 62-68.

Cowan, M.M. (1999) Plant products as antimicrobial agents. Clinical Microbiology Reviews 12, 564-582.

Cragg, G.M., Newman, D.J. \& Weiss, R.B. (1997) Coral reefs, forests, and thermal vents: the worldwide exploration of nature for novel antitumor agents. Seminars in Oncology 24,156-163.

Creagh, T., Ruckle, J.L., Tolbert, D.T., Giltner, J., Eiznhamer, D.A., Dutta, B., Flavin, M.T. \& $\mathrm{Xu}$, Z. (2001) Safety and pharmacokinetics of single doses of (+)-calanolide A, a novel, naturally occurring nonnucleoside reverse transcriptase inhibitor, in healthy, human immunodeficiency virus negative-negative human subjects. Antimicrobial Agents and Chemotherapy 45, 1379-1386.

Currens, M.J., Gulakowski, R.J., Mariner, J.M., Moran, R.A., Buckheit, R.W. Jr., Gustafson, K.R., McMahon, J.B. \& Boyd, M.R. (1996) Antiviral activity and mechanism of action of calanolide A against the human immunodeficiency virus type-1. Journal of Pharmacology and Experimental Therapeutics 279, 645-651.

Davis, R.H. \& Leitner, M.G. (1989) Wound healing, oral and topical activity of Aloe vera. Journal of American Podiatric Medical Association 79, 559-562.

Davis, R.H. \& Rosenthal, K.Y., (1989) Processed Aloe vera administered topically inhibits inflammation. Journal of American Podiatric Medical Association 79, 395 397.

Eloff, J.N. (1999) The antibacterial activity of 27 Southern African members of the Combretaceae. South African Journal of Science 95, 148-152.

Fyhrquist, P., Mwasumbi, L., Haeggstrom, C.A., Vuorela, H., Hiltunen, R. \& Vuorela, P., (2004) Antifungal activity of selected species of Terminalia, Pteleopsis and Combretum (Combretaceae) in Tanzania. Pharmaceutical Biology 42, 308-317.

Harnett, S.M., Ooosthuizen, V. \& Van de Venter, M. (2005) Anti-HIV activities of organic and aqueous extracts of Sutherlandia frutescens and Lobostemon trigonus. Journal of Ethnopharmacology 96, 113119. 
Inman, W.D. \& Reed, M.J. (1997) Triterpenoid compound for the treatment of diabetes. In: U.S. Patent. South San Francisco, CA: Shaman Pharmaceuticals.

Inman, W.D. \& Luo, J. (1998) Hypoglycemic agents from Harungan or Vismia spp. WO 98 25,639. In: U.S. Patent. South San Francisco, CA: Shaman Pharmaceuticals.

King, H., \& Rewers, M. (1993) Global estimates for prevalence of diabetes mellitus and impaired glucose tolerance in adults. WHO Ad Hoc Diabetes Reporting Group. Diabetes Care 16, 157-177.

Li, B.Q., Fu, T., Yan, Y.D., Baylor, N.W., Ruscetti, F.W. \& Kung, H.F. (1993) Inhibition of HIV infection by baicalin - a flavonoid compound purified from Chinese herbal medicine. Cellular and Molecular Biology Research 39, 119-124.

Luo, J., Chuang, T., Cheung, J., Quan, J., Tsai, J., Sullivan, C., Hector, R.F., Reed, M.J., Meszaros, K., King, S.R., Carlson, T.J. \& Reaven, G.M. (1998) Masoprocol (nordihydroguaiaretic acid): a new antihyperglycemic agent isolated from the creosote bush (Larrea tridentata). European Journal of Pharmacology 346, 77-79.

Luo, J., Cheung, J., Yevich, E.M., Clark, J.P., Tsai, J., Lapresca, P., Ubillas, R.P., Fort, D.M., Carlson, T.J., Hector, R.F., King S.R. Mendez, C.D., Jolad, S.D. \& Reaven, G.M. (1999) Novel terpenoid-type quinones isolated from Pycnanthus angolensis of potential utility in the treatment of type 2 diabetes. Journal of Pharmacology and Experimental Therapeutics 288, 529-534.

McCluggage, D. \& Higdon, P.L. (1999) Holistic Care for Birds: A Manual of Wellness and Healing. Wiley Publishers.

Meshnick, S.R., Taylor, T.E. \& Kamwonwongpaisan, S. (1996) Artemisinin and the antimalarial endoperoxides: from herbal remedy to targeted chemotherapy. Microbiology Reviews 60, 301-315.

Moshi, M.J. \& Mbwambo, Z.H. (2005) Some pharmacological properties of extracts of Terminalia sericea roots. Journal of Ethnopharmacology 97, 43-47.
Motsei, M.L., Lindsey, K.L., van Staden, J. \& Jager, A.K. (2003) Screening of traditionally used South African plants for antifungal activity against Candida albicans. Journal of Ethnopharmacology 95, 235-241.

Naik, A.D. \& Juvekar, A.R. (2003) Effects of alkaloidal extract of Phyllanthus niruri on HIV replication. Indian Journal of Medical Sciences 57, 387-393.

Notka, F., Meier, G. \& Wagner, R. (2004) Concerted inhibitory activities of Phyllanthus amarus on HIV replication in vitro and ex vivo. Antiviral Research 64, 93102.

Piras, G., Makino, M. \& Baba, M. (1997) Shosaiko-to, a traditional Kampo medicine, enhances the anti-HIV-1 activity of lamivudine (3TC) in vitro. Microbiology and Immunology 41, 835-839.

Pulse, T.L. \& Uhlig, E. (1990) A significant improvement in a clinical pilot study utilizing nutritional supplements, essential fatty acids and stabilized Aloe vera juice in 29 HIV seropositive, ARC and AIDS patients. Journal of Advancement in Medicine 3, 4.

Sato, Y. (1990) Protection effects of Aloe arborescens on skin injury by $\mathrm{X}$-irradiation. Yakmgakn Zasshi 110, 876-884.

Sneader, W. (1985) Drug Discovery: The Evolution of Modern Medicines. New York:Wiley.

Sun, I.C., Chen, C.H., Kashiwada, Y., Wu, J.H., Wang, H.K. \& Lee, K.H. (2002) Anti-AIDS AGENTS 49. synthesis, anti-HIV, and antifusion activities of IC9564 analogues based on betulinic acid. Journal of Medicinal Chemistry 12, 4271-4275.

Uchiumi, F., Hatano, T., Itoh, H., Yoshida, T. \& Tanuma, S. (2003) Transcriptional suppression of the HIV promoter by natural compounds. Antiviral Research 58, 89-98.

Van Everbroeck, B., Pals, P., Dziedzie, T., Dom, R., Godfraind, C., Sciot, R., Brucher, J.M., Martin, J.J. \& Cras, P. (2000) Retrospective study of Creutzfeldt-Jakob disease in Belgium: neurophysiological findings. Acta Neoropathologica (Berl) 99, 358-364.

Vlietinck, A.J., De Bruyne, T., Apers, S. \& Pieters, L.A. (1998) Plant-derived leading 
compounds for chemotherapy of human immunodeficiency virus (HIV) infection. Planta Medica 64, 97-109.

Wang, H.K., Xia, Y., Yang, Z.Y., Natschke, S.L. \& Lee, K.H. (1998) Recent advances in the discovery and development of flavonoids and their analogues as antitumor and antiHIV agents. Advances in Experimental Medicine and Biology 439, 191-225.

WHO (1989) In vitro screening of traditional medicines for anti-HIV activity: memorandum from a WHO meeting. Bulletin of the World Health Organization 67, 613-618.

WHO (2002) Traditional Medicine: Growing Needs and Potential. WHO Policy Perspectives on Medicines. World Health Organization, Geneva pp. $1-6$.
Xu, Z.Q., Barrow, W.W., Sulling, W.J., Westbrook, L., Barrow, E., Lin, Y.M. \& Flavin, M.T. (2004) Anti-HIV natural product (+)calanolide $\mathrm{A}$ is active against both drugsusceptible and drug-resistant strains of Mycobacterium tuberculosis. Bioorganic Medicinal Chemistry 12, 1199-1207.

Yoshida, T., Itoh, H., Hatano, T., Kurata, M., Nakanishi, T., Inada, A., Murata, H., Inatomi, Y., Matsuura, N., Ono, K., Nakane, H., Noda, M., Lang, F.A. \& Murata, J. (1996) New hydrolyzable tannins, shephagenins $\mathrm{A}$ and $\mathrm{B}$, from Shepherdia argentea as HIV-1 reverse transcriptase inhibitors. Chemical and Pharmaceutical Bulletin (Tokyo) 44, 14361439. 